\title{
Prostituição feminina em Goiânia: entendendo contextos identitários
}

\author{
Rogério A raújo da Silva*
}

\begin{abstract}
Resumo: O presente artigo é parte de uma pesquisa realizada junto a um grupo de mulheres que se prostituem na cidade de Goiânia, Goiás, que resultou em minha dissertação de mestrado. Com base em dados dotidos por meio de pesquisa empírica, esse estudo discate aspectos relacionadbs à construção da identidade da profissional do sexo, como as representaçães do conpo e o processo de estigmatização. Do ponto de vista teórico, minha reflexão pretende contribuir para a dessencialização e a desnaturalização db conceito de identidade, em uma perspectiva que a entende como processual, fluida e relacional.
\end{abstract}

Palavras-chave: prostiturição; identidade; conpo.

Introdução

N este artigo, discuto aspectos relacionados ao processo de construção da identidade da profissional do sexo. Para isso, textualizo a fala dessas mulheres sobre a atividade prostituinte em suas diversas dimensões, entendendo que 0 fato de estarem na prostituição constitui um eixo norteador de suas vidas e de suas representações identitárias. Em um primeiro momento, procuro demonstrar qual percepção as mulheres profissionais do sexo têm do próprio corpo, relacionando tanto os aspectos instrumentais, quanto os expressivos do corpo e refletindo sobre as formas de produção de sentido ligadas ao ofício da prostituição. Em um segundo momento, busco compreender de que modo essas profissionais do sexo constroem suas identidades em um contexto rel acional, como essas identidades são negociadas cotidianamente e quais marcadores de diferenças são acionados para conferir inteligibilidade às representações identitárias.

\footnotetext{
* M estre em Sociologia pela UFG.
}

\section{Usos e representações do corpo}

Um dos objetivos deste artigo é discutir que percepção que as mulheres profissionais do sexo têm do próprio corpo e se essa representação apresenta alguma singularidade relacionada ao ofício que exercem. Desde o início da minha pesquisa, parti do pressuposto de que esse grupo não poderia ser homogêneo no que tange às representações simbólicas do corpo, pois seus componentes, embora exerçam o mesmo ofício, têm percepções diferentes do corpo, decorrentes de fatores como idade, fenotipia e tempo de vivência na prostituição. Entretanto, a despeito de tais diferenças, considero que as mulheres pesquisadas compartilham um mesmo universo simbólico, com base no qual percebem e ordenam suas experiências corporais.

Para o entendimento do corpo humano como suporte de signos, apoio-me em Rodrigues (1979), que apresenta o corpo como um objeto cognitivo e afirma que, para compreendê-lo sociologicamente, é necessário apenas aplicar a ele a distinção que os sociólogos formulam entre os chamamos aspectos instrumentais e os expressivos do comportamento humano. Decor- 
rentes desses aspectos, tem-se, respectivamente, a atividade instrumental do corpo, da qual se procura saber para que ele serve, e a atividade expressiva, que é simbólica, à qual convém indagar o que está sendo dito. N esse sentido, estudar a apropriação simbólica do corpo é estrategicamente importante para os cientistas sociais, uma vez que ele é, sem dúvida, o primeiro patrimônio que o homem possui. Entretanto, ainda segundo Rodrigues (1979), mesmo que o homem assuma seu corpo como "natural" e "universal", a mais simples observação em torno dele poderá demonstrar que o corpo humano como sistema biológico é formatado pela religião, pela ocupação, pelo grupo familiar, pela classe social e por outros intervenientes sociais e culturais. Nesse mesmo sentido, 0 corpo pode ser tomado como um dado social que se expressa por códigos e símbolos:

0 corpo porta em si a marca da vida social, expressa-o a preocupação de toda sociedade em fazer imprimir nele, fisicamente, determinadas transformações que escolhe de um repertório cujos limites virtuais não se podem definir. Se considerarmos todas as modelações que sofre, constataremos que o corpo é pouco mais que uma massa de modelagem à qual a sociedade imprime formas segundo suas próprias disposições: formas nas quais a sociedade projeta a fisionomia do seu próprio espírito [...]. Em cada sociedade poder-se-ia levantar o inventário dessas impressõesmensagens e descobrir-Ihes o código: bom caminho para se demonstrar, na superfície dos corpos, as profundezas da vida social. (Rodrigues, 1979, p.62-63)

Com base nessa perspectiva busquei, em minha pesquisa, entender como as mulheres profissionais do sexo, dentro de um quadro de aspectos expressivos e simbólicos, percebem e representam seus corpos e que tipo de sinais são emitidos por ele, ou seja, indago o que está sendo dito e o que esse corpo significa, pois, a partir daí, é possível entender a dinâmica social do grupo. Um dos eixos sobre o qual me apoiei para entender o corpo da mulher profissional do sexo é o de que a representação do seu corpo como um sistema de significação está relacionada à sua ocupação, ou seja, ao ofício de se prostituir. No início da pesquisa, julguei que el as tinham uma relação erotizada com o próprio corpo, com base na qual buscavam artifícios para se tornarem atraentes a todo custo, visto que, no jogo da atração e da sedução entre a profissional do sexo e seu possível cliente, seria utilizada predominantemente a performance corporal.

Para entender o corpo e sua relação com o aspecto da atividade instrumental, ou seja, compreendê-lo em seu sentido mais utilitarista, sustento-me em M auss (1974), que elabora a seguinte concepção de técnica corporal:

Entendo por essa pal avra as maneiras como os homens, sociedade por sociedade e de maneira tradicional, sabem servir-se de seus corpos [...] as técnicas possuem uma especificidade, mas esta especificidade é o caráter de todas as técnicas. Toda técnica propriamente dita tem sua forma. (M auss, 1974, p. 211-213)

Para que se possa compreender o sistema de técnicas corporais, é necessário entender, primeiramente, que el e segue al guns princípios de classificação, como a divisão por sexo e idade. No entanto, na minha pesquisa, o maior interesse refere-se à classificação das técnicas corporais em sua relação com o rendimento. Para M auss (1974, p.220), "as técnicas corporais podem classificar-se em relação a seu rendimento, em relação aos resultados do treinamento. 0 treinamento, como a montagem de uma máquina, é a procura, a aquisição de um rendimento". Essa perspectiva de técnica corporal pode ser remetida, assim como em outras ocupações, para o ofício da prostituta que utiliza o corpo no jogo da sedução com o cliente. Em virtude da sua ocupação, o corpo da mulher profissional do sexo passaria por todo um processo de treinamento, no qual sua maneira de se vestir, de andar, de ol har e de se comportar estaria intimamente ligada ao jogo da sedução e da atração. Pode-se considerar, também, que esse processo de construção esteja relacionado à busca de uma eficácia, pois o objetivo da profissional do sexo é, prioritariamente, a obtenção de favores ou de dinheiro.

Como descreve Gaspar (1985) em sua pesquisa com profissionais do sexo de Copa- 
cabana, Rio de Janeiro, nas boates, a maioria das profissionais do sexo usa calças compridas muito justas e collants de lycra, um tecido que tem grande demanda pela capacidade de modelar o corpo, em cores fortes: amarelo, dourado, prateado, vermelho. A elasticidade permite que as calças compridas e 0 collant sejam extremamente justos, ressal tando os contornos das nádegas e pernas, marcando a curva da cintura e o volume dos seios. Já o uso corrente dos saltos altos, que produzem uma elegância de porte pelo alongamento das pernas, é uma exi gência tanto no período da tarde quanto da noite. $E$ a maquiagem, também sempre presente, põe em foco os olhos, órgãos privilegiados como emissores de significados, principalmente no campo dos envolvimentos eróticos. Esse apelo sensual à vestimenta é corroborado pela postura corporal e pelo conjunto de gestos.

A aparência ea performance das mulheres profissionais do sexo pesquisadas pela autora, mulheres jovens de classe média, que se prostituem em boates da Zona Sul do Rio, correspondem à imagem que, geralmente, se tem da prostituta. A s profissionais do sexo entrevistadas por mim, entretanto, não se enquadram nessa imagem, são provenientes de camadas populares e prostituem-se nas ruas. $E$ mesmo que seu corpo tenha passado por um processo de treinamento no que se refere à maneira de andar e de se comportar para atrair o cliente, as percepções das mulheres ouvidas em minha pesquisa divergem em alguns aspectos dos estereótipos atribuídos às profissionais do sexo.

Em princípio, poder-se-ia pensar que a percepção do corpo entre mulheres que se prostituem seria extremamente sexualizada e erotizada em razão do ofício que exercem. Entretanto, mesmo que a erotização esteja presente nos relatos que essas mulheres fazem de si, percebe-se que elas apresentam outras formas de significação do corpo.

0 uso das técnicas corporais, no caso dessas mulheres, está ligado intimamente à dissociação entre corpo e prazer e corpo e sentimento. N ormalmente, no que se refere à mulher profissional do sexo e suas práticas sexuais, há a indagação: a mulher profissional do sexo sente ou não prazer em suas relações sexuais com os clientes? 0 que pude observar nos depoimentos das mulheres pesquisadas é que há intencional idade em dissociar o corpo do prazer. Essa dissociação dá-se no processo de aprendizado do ofício. As profissionais dizem que, na maioria das vezes, quando estão com 0 cliente, seu único objetivo é proporcionar-Ihe prazer mecanicamente. Entretanto, al gumas mulheres confessaram que, eventualmente, se o cliente for carinhoso ou se el as sentirem al guma atração por ele, o prazer pode ocorrer, mas isso é al go bastante raro. Há, por parte das mul heres, uma idéia de dissociação entre corpo, sentimento e prazer, elementos que, na concepção do amor romântico, não podem ser dissociados. Por isso, procurei entender qual o significado das noções de afeto, sexo e prazer para essas mulheres.

U m dos aspectos abordados na pesquisa que pode ser remetido a essas noções de carinho e afeto entre as profissionais do sexo está relacionado ao beijo na boca, prática que constitui um tabu para elas. 0 que pude perceber por meio de conversas e entrevistas com as profissionais do sexo é que o beijo na boca tornase um divisor simbólico entre sexo e sentimento. Há quase que um consenso entre as mulheres que se prostituem em não beijarem nem deixarem ser beijadas, o que, em muitos casos, pode gerar uma situação de conflito, caso 0 cliente queira beijá-las no ato do programa. $\mathrm{Na}$ avaliação delas, o beijo está relacionado ao sentimento:

Eu acho que o beijo na boca é uma coisa muito íntima. E aquilo ali pra gente não é uma coisa íntima, aquilo ali pra nós é uma coisa de momento é uma coisa que a gente não tá ali por prazer, por sentimento, por tesão, a gente tá ali por dinheiro, tanto que, se os homens dessem o dinheiro pra gente e não levasse pra cama, seria bem melhor. Pra nós seria uma maravilha, mas a gente tá ali pelo dinheiro, a gente não tá ali por amor, por prazer ou por uma atração. Então um beijo na bocaé uma coisa muito íntima. Eu imagino assim, é uma coisa íntima, é uma coisa quando você gosta, quando você tá apaixonada. Então, é você não ter aquela intimidade com o freguês, aquele laço. (Dados de entrevista)

0 que pude perceber é que o beijo na boca, assim como o prazer, pode ocorrer eventual- 
mente com o cliente, embora isso seja muito raro. A alegação por parte delas é a de que 0 beijo, como registrado anteriormente, estaria relacionado ao carinho e ao afeto, sentimentos que não são associados aos clientes. Em sua concepção, a prática de beijar na boca está associada somente ao companheiro ou ao parceiro com quem elas mantêm uma relação mais estável. 0 utro argumento usado para evitar o beijo na boca é que o beijo pode despertar um sentimento de afeto pelo cliente, o que representa um risco para a mulher profissional do sexo. U ma entrevistada relatou-me que 0 ato de beijar um cliente ou deixar ser beijada sempre é evitado pela profissional do sexo, confessando-me que ela mesma já teve essa atitude e que acabou se apaixonando pelo cliente, o que, na sua avaliação, é algo extremamente negativo, pois "a mulher prostituta jamais deve se apaixonar por um cliente, porque isso é um romance sem futuro".

0 uso do preservativo é outro ponto que constitui um divisor simbólico entre sexo e sentimento para as mulheres pesquisadas. N os relatos, foi-me possível obter a informação de que, nas relações sexuais com os clientes, 0 principal requisito é o uso do preservativo, o que não ocorre quando se trata do companheiro ou parceiro fixo. $\mathrm{Na}$ concepção delas, 0 uso do preservativo está associado ao cliente, ou seja, à pessoa com quem se deve tomar precauções. $N$ ão vêem riscos e necessidade em usá-lo com o parceiro, por acreditarem que, com eles, elas estão seguras. Desse modo, há dois aspectos que norteiam a divisão simbólica que essas mulheres fazem entre 0 sexo e sentimento: 0 beijo na boca e o uso do preservativo. A relação com os clientes está sempre embasada na idéia do sexo sem sentimento, de não beijar na boca e o constante uso do preservativo. Já com 0 companheiro, o sexo está associado ao carinho, ao afeto e, conseqüentemente, ao beijo na boca e à dispensa do preservativo. Desse modo, as profissionais do sexo criam, ao dissociarem corpo e sentimento, formas de representação singulares que se manifestam em atitudes e comportamentos claramente definidos.

$N$ o decorrer da pesquisa pude perceber que as mulheres profissionais do sexo têm alguns cuidados específicos com o corpo, em virtude do ofício que exercem, e que, embora a questão da estética e da sensualidade não deixe de ser mencionada, elas são colocadas, na maioria dos depoimentos, em segundo plano, sendo o corpo percebido como um instrumento de trabal ho que exige manutenção para um bom funcionamento:

Eu não paro pra pensar sobre meu corpo. Eu paro pra olhar como uma profissional. Então eu me vejo assim - eu tô ali pra fazer o cara gozar, eu faço ele gozar e o serviço tá feito. Eu não paro pra me observar. Eu acho que a importância do meu corpo é eu tá sadia, e eu me prevenir das doenças e eu me cuidar. Em relação ao meu corpo, eu sempre procuro um ginecologista, se eu tô sentindo alguma coisa eu sempre tomo os remédios devidos que eu tenho que tomar, eu uso o preservativo. Você tá entendendo? Então eu não abuso do meu corpo, pra falar - Não, eu não to nem aí! Se pegar pegou! Não, sem preservativo eu não transo com ninguém por preço nenhum. Já fiz até ultra-sonografia intravaginal, porque mesmo com o preventivo às vezes não dá uma doença, mas fazendo um exame mais minucioso, dá pra prever. (Dados de entrevista)

Nos depoimentos das mulheres, é sempre recorrente a preocupação em evitar as doenças sexual mente transmissíveis (DST) ou a Aids. Elas têm medo de ficar doentes, o que as tornaria impossibilitadas de trabal har, o que é expresso na observação de uma entrevistada: "0 meu corpo é tudo, se eu ficar doente como é que eu vou trabalhar, como vou cuidar dos meus filhos?". Essa concepção utilitarista do corpo entre mulheres de camadas populares foi também registrada por Carval ho (2002), em sua pesquisa com mulheres portadoras de câncer de mama:

Esse orgulho de ser saudável, de não adoecer constantemente, remete também à concepção utilitarista do próprio corpo. Ou seja, a idéia que el as têm é a de um corpo instrumental izado para a maternidade, para a produção, para 0 trabalho, para a manutenção da subsistência; afinal, elas são integrantes da classe trabaIhadora urbana, cuja forma de sobrevivência repousa no uso da força física. (Carvalho, 2002, p. 28) 
A preocupação em manter um corpo saudável pode ser aferida por meio dos dados de uma pesquisa sobre DST/A ids em Goiânia, ${ }^{1}$ na qual $84 \%$ das profissionais do sexo afirmaram que não fazem sexo com clientes sem uso do preservativo, o que foi corroborado por meu trabal ho de campo. Naquela mesma pesquisa, foi perguntado à mul her profissional do sexo se o dinheiro é mais importante do que correr 0 risco de contrair uma doença sexualmente transmissível e $98 \%$ das entrevistadas disseram que não. Entretanto, pelos relatos de algumas entrevistadas, obtive a informação de que existem muitas mulheres que ainda fazem programas sem 0 uso do preservativo. Isso quando o cliente, no momento da negociação do programa, oferece um valor mais alto para que não seja usado o preservativo. No trabal ho de campo, também obtive 0 dado de que a maioria dos clientes ainda pede para fazer 0 programa sem o uso do preservativo, al egando que estão saudáveis. Entretanto, as profissionais do sexo utilizam argumentos e táticas para convencê-los a usar o preservativo:

Quando o cliente pede pra transar sem 0 preservativo, geral mente el es falam e al egam: $\mathrm{N}$ ão, eu sou casado, eu não tenho nada não. A i eu, é claro! Para não ofender ele, né? Eu falo: Não, meu bem, eu tenho medo não é de você, eu não confio é na sua mulher, vai que ela não tá dando só pra tu? (Dados de entrevista)

Como se pode observar, uma das táticas de persuasão que as mulheres usam com 0 cliente é colocar sobre a esposa dele a dúvida do contágio. Outra forma de evitar a realização do programa sem o uso do preservativo e, conseqüentemente, o risco de contaminação por DST/Aids é o uso do preservativo feminino. U ma das táticas utilizadas por elas é colocá-lo no ato do programa sem que o cliente perceba. Entretanto, seu uso por parte das mulheres que se prostituem em Goiânia ainda é pequeno, em virtude do seu valor el evado em comparação com o preservativo masculino. 0 utro fator que contribui para o não-uso desse tipo de preser-

1. Pesquisa realizada pelo Projeto Flor de Pequi, no ano de 2003, com mulheres profissionais do sexo. vativo é a resistência por parte de algumas mulheres, que dizem quejá o experimentaram e não gostaram.

Quanto à manutenção de um corpo saudável, para a maioria das profissionais do sexo, 0 uso de drogas e bebidas al coólicas é visto como al go negativo: a maioria das entrevistadas diz não consumir drogas ou bebida alcoólica por acreditar que 0 uso de tais substâncias pode acarretar problemas, como o desgaste do corpo. Entretanto, na pesquisa realizada pelo Projeto Flor de Pequi, verificou-se que cerca de $50 \%$ das mulheres consomem álcool ou droga diariamente. Eu mesmo pude constatar, por meio de conversas informais, que as drogas mais comuns são a merla e a maconha, havendo, desse modo, uma divergência entre o que é dito por elas e a prática cotidiana.

Outro fator ligado ao corpo da profissional do sexo está relacionado a aspectos como beleza e estética. $N$ as entrevistas, ao serem questionadas sobre a importância da estética para a atração de clientes, algumas entrevistadas afirmam que os cuidados estéticos com 0 corpo e a vestimenta são importantes no jogo da sedução:

O cuidado com o meu corpo tem $80 \%$ de importânciano meu trabalho. 0 homem vêmuito isso, sabe? Eu sempre procurei manter bem 0 corpo, porque... Olha! Eu não sei as outras, mas comigo o que vale é o corpo. Eu não sou de fazer academia, porque eu não tenho tempo. $M$ as eu procuro diminuir na massa, se eu comer arroz, eu não como macarrão, e assim viceversa, tudo que você pensar eu como, só que com moderação, se eu tomar sorvete hoje, eu fico um mês sem tomar sorvete, se eu tomar Coca-C ola hoje, eu não tomo por uma semana, assim eu vou controlando, e toda a vida eu mantenho o mesmo corpo. (Dados de entrevista)

Já em relação à vestimenta e a outros artifícios como salto al to e maquiagem, a mesma entrevistada relatou-me que prefere usar roupas mais sensuais, como saias bastante curtas, calças coladas ao corpo e blusas também bastante curtas. J ustifica que os homens, de um modo geral, gostam de ver pernas bonitas e nádegas bem-feitas e roupas mais provocantes 
que expõem partes do corpo são atrativos para eles. Dá ênfase, também, para o uso do salto al to. "Já o sal to alto, eu acho que toda mulher deveria usar salto alto, não é nem tanto em serviço, sei lá, é uma elegância, não sei se é porque eu me sinto tão bem em cima do onze."

Outra entrevistada, mesmo colocando a preocupação com a estética como algo secundário, avalia que os cuidados em relação à beleza são importantes. $\mathrm{Na}$ sua concepção, 0 principal cuidado que a profissional do sexo deve ter é com o uso do preservativo: "o primeiro cuidado que eu tenho a partir do momento que eu entro com aquele homem pra dentro do quarto é exigir a camisinha". O utra preocupação é com sua aparência física. "O outro cuidado que eu tenho também, equando eu fico em casa, aí eu vou bronzear, às vezes eu vou pintar 0 cabelo, tirar a sobrancelha, ficar diferente, porque o homem gosta de mulher diferente." A o ser questionada sobre o que viria a ser uma mulher diferente, a entrevistada responde que:

M ulher diferente não é aquela mulher que vem aqui, e fica um ano aqui com a mesma cara. Tem que mudar! Tem que cortar o cabelo! 0 meu cabelo era grande! A í eu cortei, às vezes eu faço escovinha. Aí ela se torna uma mulher diferente. Porque se você vir do mesmo jeito, ficar um ano num lugar com a mesma cara, com o mesmo modo de roupa, aí não tem jeito. Então é por isso que você tem sempreque ficar bonita, pintar o cabelo, fazer a sobrancel ha, fazer unha, comprar roupa nova, pra incentivar o homem, porque já tá na rua com umas duzentas mulheres! Porquejá tem várias mul heres aí né? A rrumadinha, bonitinha, aí você vem sem maquiagem, sem escovinha, com cabel o bagunçado, unha bagunçada, aí você não consegue nada. Você vai ficar andando o dia intei rinho nessa rua à toa. (Dados de entrevista)

Entretanto, os cuidados com a vestimenta e com a aparência, de um modo geral, não são uma regra entre as mulheres que se prostituem nas ruas de Goiânia. A maioria dessas mulheres veste-se de forma muito simples, sem se preocupar muito com a aparência. É comum encontrar mulheres usando apenas short, camiseta e uma sandália havaiana e sem nenhum vestígio de maquiagem ou qualquer outro artifício de sedução. No entanto, deve-se considerar que essas mulheres pertencem às classes populares, para quem a saúde e a possibilidade de ter um corpo apto para o trabalho e para a subsistência assumem importância maior do que a estética e a beleza.

\section{Negociando identidades}

Nos trabalhos que se propõem a compreender a prostituição, é recorrente a tentativa de entender como se constrói a identidade dos indivíduos que se dedicam ao ofício de prostituirse. Alguns trabalhos, como o de Espinheira (1984), fazem um estudo da prostituição e, em particular, dos indivíduos que se prostituem, da perspectiva do estigma, compreendendo que seu comportamento, visto como desviante, tem um grande peso e um caráter totalizador, que se sobrepõe aos demais papéis, contaminando as outras esferas da vida pessoal de seus praticantes. Entretanto, esse aspecto totalizador da identidade do indivíduo estigmatizado pode ser entendido dentro de um contexto menos essencialista, pois, no processo de construção da identidade da profissional do sexo, ocorre uma forte tensão entre esse aspecto totalizador da sua identidade e um espaço razoável para a negociação deste e de outros papéis sociais por ela desempenhado.

Neste artigo, quando busco compreender de que modo as profissionais do sexo constroem suas identidades, tomo como perspectiva um contexto relacional no qual estas são negociadas cotidianamente à maneira dos trabalhos de Gaspar (1985) e Freitas (1985).

Em seu estudo, Gaspar (1985) analisa a construção da identidade de uma profissional do sexo, tendo como foco o jogo de atributos que são postos na interação estabelecida entre ela e os clientes. A autora estrutura sua análise em duas direções: a investigação da identidade da profissional do sexo com base nas representações dos clientes, ou seja, como as profissionais do sexo são percebidas por eles; e a autorepresentação dessas profissionais, enfocando, em particular, suas manipulações e racionalizações diante dos preconceitos que envolvem sua atividade. A nalisa, também, a figura do cliente e de que forma ele é visto pelas profissionais, pois tais reflexões, na avaliação da 
autora, são um caminho para o entendimento da autodefinição da profissional do sexo.

Já Freitas (1985) trabalha com outra perspectiva: a de que a identidade da profissional do sexo pode ser compreendida pelo estudo da autoconcepção das prostitutas, em função do contexto de exercício da atividadee dos padrões de interação que se estabelecem entre elas e os atores significativos de seu ambiente, como colegas, clientes, cafetinas, rufiões e familiares. Isso permite a distinção de três dimensões da identidade da prostituta: uma primeira construída por um critério físico (prostitutas de bordel ou de "rua"); uma segunda, por um critério moral (padrões de conduta da prostituta), e uma última, por um critério afetivo (negociação de um padrão de afetividade com clientes, colegas, rufiões, cafetinas e família).

Em um contexto mais amplo para o entendimento da construção da identidade do indivíduo contemporâneo, $\mathrm{H}$ all (2002) trabal ha com a perspectiva de que as identidades modernas estão sendo "descentradas", isto é, estão sendo deslocadas e fragmentadas. $\mathrm{Na}$ avaliação do autor, o sujeito está se tornando fragmentado, composto não de uma única, mas de várias identidades, algumas vezes contraditórias ou não resolvidas. 0 próprio processo de identificação entre o sujeito e as formas culturais de representação tornou-se mais provisório, variável e problemático:

A identidade torna-se uma "cel ebração móvel": formada e transformada continuamente em relação às formas pelas quais somos representados ou interpelados nos sistemas culturais que nos rodeiam. [...] 0 sujeito assume identidades diferentes em diferentes momentos, identidades que não são unificadas ao redor do "eu" coerente. Dentro de nós há identidades contraditórias, empurrando em diferentes direções, de tal modo que nossas identificações estão sendo continuamente deslocadas. (Hall, 2002, p. 12-13).

U ma outra autora que trabal ha também com a perspectiva de que as identidades são fragmentadas é Woodward (2000), ao operar com a idéia de que a identidade se constrói pela diferença. Para a autora, a primeira perspectiva que se deve ter é a de que a identidade é relacional, ou seja, a identidade, para existir, depende de algo fora dela, ou seja, de uma identidade que ela não é, mas que, entretanto, fornece condições para que ela exista. Sendo assim, a identidade é marcada pela diferença, que é sustentada pela exclusão: se o indivíduo é uma coisa, não pode ser outra. A crescenta ainda que a identidade pode ser entendida em duas dimensões: as perspectivas essencial istas e nãoessencialistas. U ma definição essencialista da identidade de um grupo sugeriria que existe um conjunto autêntico de características de que todos do grupo partil ham e que não se al tera ao longo do tempo. U ma definição não-essencialista focaliza as diferenças, assim como as características comuns ou partilhadas, tanto entre os próprios membros do grupo quanto com membros de outros grupos.

Segundo a autora citada, para que se compreenda como a identidade funciona, é preciso conceitualizá-la e dividi-la em suas diferentes dimensões. Com freqüência, a identidade envolve reivindicações essencial istas sobre quem pertence e quem não pertence a um determinado grupo identitário. A identidade, aí, é vista como fixa e imutável. A lgumas vezes, essas reivindicações estão baseadas em aspectos concebidos como naturais, como a etnia, a raça e as relações de parentesco. A autora afirma ainda que a identidade é rel acional, e sua diferença é estabelecida por uma marcação simbólica relativamente a outras identidades. Para isso, cita as identidades nacionais, nas quais os sistemas representacionais que marcam a diferença podem se materializar por meio de um uniforme, uma bandeira nacional ou até mesmo pelo tipo de produto que se consome em determinado país. Nesse sentido, a identidade está vinculada também a condições sociais e materiais, como o hábito de consumir determinado produto. 0 social e o simbólico referemse a dois processos diferentes, embora cada um deles seja necessário para a construção e a manutenção das identidades. A marcação simbólica é 0 meio pelo qual se atribui sentido a práticas e a relações sociais, definindo, por exemplo, quem é excluído e quem é incluído. É por meio da diferença social que essas classificações da diferença são "vividas" nas relações sociais. 
Outro aspecto importante da conceitualização da identidade é o exame dos sistemas classificatórios que mostram como as relações sociais são organizadas e divididas, como a oposição entre o "nós" e o "eles". N o processo de construção de identidades, algumas diferenças são marcadas, mas outras podem ser obscurecidas: por exemplo, a identidadenacional pode omitir diferenças de classe e diferenças de gênero. A autora observa que as identidades não são unificadas, pode haver contradições no seu interior que devem ser negociadas. Por exemplo, um indivíduo pode sever em uma difícil negociação ao dizer que todos no grupo são iguais, mas, ao mesmo tempo, fundamentalmente diferentes. $E$, por fim, para 0 entendimento do processo de construção da identidade, deve-se também levar em conta o nível psíquico, pois trata-se de uma dimensão que, juntamente com a simbólica e a social, é necessária para uma completa conceitual ização da identidade.

Em minha pesquisa, pude verificar que, quando se reflete sobre o processo de construção da identidade da profissional do sexo, observa-se que, de um modo geral, ela é essencializada. Quando descritas pela maioria das pessoas, as profissionais do sexo são classificadas como sendo todas iguais, recebendo adjetivos como perigosas, sedutoras, escandalosas e violentas, características consideradas inerentes a toda e qualquer prostituta e que conferem a esse grupo um conjunto preciso de atributos que são partil hados por todos do grupo e que não se alteram. Entretanto, partindo-se de uma perspectiva não-essencialista e relacional, pode-se verificar que:

As identidades são fabricadas por meio da marcação da diferença. Essa marcação da diferença ocorre tanto por meio de sistemas simbólicos de representação quanto por meio de formas de exclusão social. A identidade, pois, não é 0 oposto da diferença: a identidade depende da diferença. $\mathrm{N}$ as relações sociais, essas formas de diferença - a simbólica e a social - são estabelecidas, ao menos em parte, por meio de sistemas classificatórios. Um sistema classificatório aplica um princípio de diferença a uma população de uma forma tal que seja capaz de dividi-la (e a todas suas características) em ao menos dois grupos opostos - nós/eles; eu/outro. (Woodward, 2000, p.39-40)

A o estudar o processo de construção da identidade da profissional do sexo, pude observar que os discursos operam no sentido de marcar uma diferença que é sempre relacional. Entre as mulheres que se prostituem, há normalmente uma noção de diferença que se apóia em formas de conduta e atitudes que, acreditam elas, as diferenciam entre si. N esse sentido, a identidade dessas mulheres torna-se relacional à medida que, para ser construída, depende de algo fora dela, ou seja, para que a mulher crie uma autorepresentação de si mesma, é necessário que exista uma identidade que ela não é, ou seja, o outro.

Desse modo, caso se tome como eixo norteador para 0 entendimento dessas identidades a perspectiva de que a identidade é marcada pela diferença e que as diferenças são marcadas por sistemas simbólicos, sendo que estes, por sua vez, podem ser visualizados e entendidos por meio de um sistema classificatório, pode-se verificar que entre as profissionais do sexo do Dergo, em particular, há um sistema classificatório no qual há duas categorias distintas de diferenciação. Essa classificação leva em consideração alguns aspectos como a conduta, os hábitos e posturas em relação às mulheres que se prostituem no local, o que resulta em dois grupos de mulheres, as chamadas noiadas, termo pejorativo referente às mulheres profissionais do sexo que são usuárias de drogas, classificadas como as "outras", e "nós", as garotas de programa ou profissionais do sexo. No sistema classificatório dessas mulheres, há uma hierarquia na qual as chamadas noiadas são vistas como as mul heres que menos valor têm, pois fazem sexo sem preservativo e a elas são atribuídos adjetivos como ladra, drogada e bagunceira.

Para que eu pudesse entender de que forma se estrutura esse sistema nativo de classificação, nas entrevistas realizadas durante a pesquisa a primeira questão proposta foi: como você se define e como também define suas colegas de trabal ho? Foram apresentados para a entrevistada termos como prostituta, garota de programa, profissional do sexo ou traba- 
Ihadora do sexo. Embora inicialmente muitas disseram não haver diferença entre esses termos ("São mais esses termos, garota de programa, prostituta, tem umas que fala prostituta, outras fala garota de programa. Não tem diferença não"). No decorrer da pesquisa, pude perceber que o termo prostituta éval orado negativamente:

E $u$ acho que tem muita diferença entre garota de programa e prostituta. Certo? A prostituta, geral mente ela não tem família, você pode ol har que o pouco que ela ganha ela consome tudo em droga! Ela não tá nem aí pros filhos! A gora a garota de programa, ela visa muito o campo profissional, o dinheiro, ela pensa mais na família. Ela trabal ha pra ter um estatuto melhor, você tá entendendo? Nesse caso eu me considero uma garota de programa, por esta entrevista com outras mulheres você vai ver 0 nível, até a qualidade do português, presta atenção no que eu tô te falando! É bem diferente! A prostituta é muito vulgar e a garota de programa não, ela é mais recatada, o campo dela é mais o financeiro. A outra é vândalo, não tá nem aí pra nada. E pelas entrevistas, você vai ver quem é a garota de programa e quem é a prostituta. (Dados de entrevista)

Como se pode observar, a marcação da diferença entre as mulheres profissionais do sexo é representada por um sistema classificatório hierarquizado, no qual as ditas prostitutas estão em posição inferior em relação às chamadas garotas de programa. Observei que entre as mulheres entrevistadas há um consenso sobre a conotação pejorativa do termo prostituta:

Esse nome, prostituta, é muito doído! Garota de programa émel hor. Prostituta é muito doído, prostituta! A gora eu acho que o termo garota de programa é bem mel hor do que prostituta. 0 nome prostituta é feio. Então garota de programa eu acho que fica melhor. (Dados de entrevista)

Em meu trabal ho de campo, pude observar que nenhuma mulher profissional do sexo, independentemente da colocação que Ihe é atribuída no sistema classificatório, se define como uma prostituta, mas utiliza termos como garota de programa ou profissional do sexo para fazer referência a si mesma. Entretanto, ao aprofundar minhas interpretações sobre a relação que el as estabelecem entre a prostituição como profissão, ou a ligação dessa atividade com o processo de construção de uma identidade, surge uma contradição nos depoimentos das entrevistadas. A o mesmo tempo em que utilizam expressões do tipo "aqui no meu trabal ho" ou "as minhas companheiras de trabal ho", a maioria não reconhece 0 ofício da prostituição como uma ocupação legítima.

Para refletir sobre os aspectos legítimos e legais da prostituição, um trabal ho interessante é 0 de Rios (2000). Em sua pesquisa, o autor aponta as contradições existentes na legislação brasileira em relação a essa atividade, partindo de uma perspectiva do que é moral mente reprovado pela sociedade e do que é juridicamente aceito. Pela legislação brasileira, a prática da prostituição não é considerada ato ilícito penal no direito nacional, pois os artigos 227 e 232 punem não a pessoa que comercializa seu próprio corpo sexual mente, mas aqueles mediadores ou aproveitadores da prostituição, cuja atividade é designada como lenocínio. N esse sentido, 0 autor aponta que a proibição do lenocínio e a permissão da prostituição soam, efetivamente, contraditórias. Para fundamentar sua anál ise, 0 autor reporta-se a alguns penalistas clássicos do direito brasileiro e aos critérios que estes utilizam para formular essa dupla regulação, proibitiva do lenocínio e permissiva da prostituição, mostrando que prostituição é justificada como "um mal necessário", pois, aos olhos da legislação penal, ela seria tolerada em virtude da função social que desempenha:

Satisfazer os instintos masculinos e preservar a moralidade doméstica, irremediavelmente ameaçada se a pressão do irrecusável instinto, que jamais se apaziguou na fórmula social da monogamia, vazasse dentro dos lares familiares. (Rios, 2000, p.90)

0 que se observa é que a legislação brasileira não condena a prostituição em si, mas pune como crime todos os atos e aspectos que a rodeiam, como a manutenção de uma casa de prostituição, ou qualquer atividade que a favoreça. Outra questão colocada em discussão sobre os aspectos legítimos e legais da prostituição refere-se à sua compreensão como uma ocupação profissional. A prostituição é legal- 
mente reconhecida de acordo com a Portaria n 397, de 9 de outubro de 2002, que aprova a classificação brasileira de ocupações (CBO), documento que reconhece, nomeia e codifica os títulos e descreve as características das ocupações do mercado de trabal ho brasileiro. Em sua última versão, pode-se encontrar como ocupação reconhecida a atividade de profissional do sexo procedida dos termos: garota de programa, garoto de programa, meretriz, messalina, michê, mulher da vida, prostituta, puta, quenga, rapariga, trabalhador do sexo, transexual (profissional do sexo), travesti (profissional do sexo). A última atualização desse documento teve como justificativa as profundas mudanças ocorridas no cenário cultural, econômico e social no país nos últimos anos. Entretanto, mesmo que a atividade de profissional do sexo seja reconhecida como uma ocupação pela CBO, ela ainda não foi regulamentada nos termos da legislação trabalhista.

0 que pude constatar entre as profissionais do sexo é que a ocupação da prostituição não é percebida por elas como uma atividade profissional legítima ou reconhecida socialmente, o que torna contraditório seu discurso sobre o exercício da prostituição. No discurso dessas mulheres, há uma alternância de depoimentos que se contradizem, pois, ao mesmo tempo em que utilizam frases como "aqui no meu trabal ho" ou "o trabal ho que eu faço aqui", outras contrapõem-se a essas, como "quando eu sair daqui e arrumar um emprego" ou "quando eu voltar a trabalhar". Desse modo, pode-se verificar que a atividade de prostituir-se assume, em um primeiro momento, a noção de uma ocupação profissional, mas, em uma segunda avaliação, aproxima-se do consenso que há em nossa ciedade de que a ocupação da prostituição o é vista como uma atividade legítima ou moral mente aceita. $\mathrm{E}$, mesmo que termos como ofissionais do sexo ou trabal hadoras do sexo comecem a ser utilizados pelas mulheres r presentação que elas têm do ofício que e ercem ainda é contraditória.

A maioria dos trabalhos que enfocam a nstrução da identidade da profissional do sexo ienta-se pela perspectiva do interacionismo s mbólico como suporte teórico, ainda que privilegiando os aspectos dessa teoria relacionados à questão do estigma, principalmente aqueles que implicam acusação. 0 tema apresenta-se, assim, como uma área de investigação na qual estão bastante explícitas as dimensões que constituem a identidade do indivíduo, como o desempenho de papéis, a situação de status e, principalmente, a manipulação da identidade.

Como aponta Gaspar (1985), o comportamento desviante tem um grande peso e um caráter totalizador, que se sobrepõe aos demais papéis, contaminando as outras esferas da vida pessoal de seus praticantes. Vários estudos sobre prostituição refletem a preocupação com esse aspecto totalizador dos comportamentos desviantes que, de fato, têm ampla repercussão na definição da identidade dos seus agentes. Em contraste com outras ocupações que, ao estipular um papel para o indivíduo, deixam margem para outras definições de sua identidade, a prostituição, devido às suas implicações morais, contamina os demais papéis. Em minha pesquisa, também pude observar que o caráter totalizador de desvio contamina as outras esferas da vida das profissionais do sexo, como a relação com a família e com os amigos. Constata-se que essa mulher empenha-se constantemente em manipular ou acobertar a sua identidade de profissional do sexo, vista por ela como uma identidade deteriorada. Sendo assim, essa identidade precisa ser acobertada para que não contamine ou prejudique o desempenho de outros papéis sociais, como o de mãe, filha ou esposa.

Goffman (1988), ao refletir sobre a identidade social do indivíduo, afirma que há uma discrepância entre a identidade social real de um indivíduo, relativa aos atributos que a pessoa real mente tem, e sua identidade virtual, que está relacionada com características potenciais ou expectativas que um indivíduo faz em relação a outro. Nesse sentido, a pessoa estigmatizada seria desacreditada, pois a ela seria atribuída uma identidade vista como real. Entretanto, quando não apresenta um estigma imediatamente aparente ou, pelo menos, não sabe que os outros os conhecem, ela torna-se uma pessoa desacreditável, e não desacreditada. 0 autor aponta, ainda, que, no estudo do estigma, é preciso se ater ao que el e chama de informação social. Essa informação social, assim como 0 
signo que ela transmite, é reflexiva e corporificada, ou seja, étransmitida pela própria pessoa a quem se refere. A I guns signos que transmitem informação social podem ser acessíveis de forma freqüente e regular e, se buscados e recebidos habitual mente, podem ser chamados de símbolos. A lguns símbolos podem automaticamente associar um indivíduo a seu status social como um distintivo militar na lapela ou uma aliança na mão esquerda. Esses mesmos símbolos, no caso da prostituição, podem associar uma mulher a tal atividade de acordo com a maneira como ela se veste ou se comporta.

Entretanto, ao se tomar os símbolos como marcas de estigma, deve-se levar em conta a sua visibilidade, pois, segundo Goffman:

Tradicional mente, a questão do encobrimento levantou o problema da "visibilidade" de um estigma particular, ou seja, até que ponto o estigma está adaptado para fornecer meios de comunicar que um indivíduo o possui. A visibilidade é, obviamente, um fator crucial. Já que é através da nossa visão que o estigma dos outros se torna evidente com maior freqüência, talvez o termo visibilidade não crie muita distorção. $N$ a verdade, o termo mais geral "perceptividade" seria mais preciso e "evidenciabilidade" mais preciso ainda. (Goffman, 1988, p. 58-59)

Contudo, deve-se considerar que nem todos os símbolos de estigma têm uma perceptividade ou uma evidenciabilidade imediata como os de ordem congênita - cor da pele - ou permanentes - uma cicatriz por mutilação, sendo possível, nesse caso, iniciar um processo de encobrimento do estigma. A inda segundo 0 autor, o processo de encobrimento da identidade estigmatizada torna-se um ciclo que pode começar com um encobrimento inconsciente que o interessado pode não descobrir nunca; daí passa-se a um encobrimento involuntário que o encobridor percebe, com surpresa, no meio do caminho; em seguida, há o encobrimento "de brincadeira", o encobrimento nos momentos não-rotineiros da vida social, como férias em viagens; a seguir, vem o encobrimento em ocasiões rotineiras da vida diária, como no trabalho e em instituições de serviço; final mente, há o desaparecimento, 0 encobrimento completo em todas as áreas da vida, segredo que só é conhecido pelo encobridor.

A lém disso, o indivíduo que tem um atributo diferencial secreto encontra-se durante a sua rotina diária em três tipos de lugar: lugares proibidos ou inacessíveis, onde pessoas de sua situação estão proibidas de ir e onde a exposição significa expulsão; lugares públicos, nos quais pessoas desse tipo são tratadas cuidadosamente e, às vezes, penosamente, como se não estivessem desqualificadas para uma aceitação rotineira quando, na verdade, de uma maneira ou de outra estão, e, por fim, há lugares retirados onde pessoas desse tipo podem se expor e perceber que não precisam esconder 0 seu estigma. Desse modo, o mundo espacial do indivíduo estará dividido em várias regiões, segundo as contingências nelas contidas para a manipulação da identidade social e pessoal.

Para que se entenda como se manipula uma identidade estigmatizada, é preciso focalizar a rotina diária do indivíduo, pois é ela que vincula as diversas situações sociais que ele vivencia. A o pesquisar a vida diária das profissionais do sexo, é possível visualizar como suas identidades são manipuladas ou acobertadas nas relações estabelecidas diariamente. U ma maneira de acobertar essa identidade é eliminar alguns signos que podem se tornar símbolos do estigma. A primeira estratégia é a mudança do nome verdadeiro. Poucas mulheres pesquisadas assumem os seus verdadeiros nomes, a maioria utiliza nomes fictícios junto ao grupo e somente com o tempo esses verdadeiros nomes são revelados e, mesmo quando isso ocorre, o nome fictício torna-se 0 usado nas relações cotidianas. Há, por parte dessas mulheres, uma tentativa evidente de esconder a sua verdadeira ocupação, principalmente para os vizinhos, já que, com a família, principalmente pais e irmãos, a manipulação da identidade torna-se mais difícil. Contudo, existem mulheres que conseguem omitir dos familiares sua verdadeira ocupação:

Da minha família só a minha mãe sabe, as minhas filhas ainda não têm idade pra saber. Eu não gosto muito de ficar assim... na casa de parentes, eu gosto da minha mãe, mas não gosto muito de ir na casa dela, eu gosto de 
ficar mais na minha, né? E u gosto mais de ficar no meu canto sozinha. (Dados de entrevista)

Outra forma de acobertar a identidade e os possíveis símbolos que associam a mulher profissional do sexo à sua verdadeira ocupação está nas roupas e no comportamento, o que faz com que elas criem divisões entre dois espaços: o da casa e o da rua. Segundo DaM atta (1987), a sociedade brasileira singulariza-se pelo fato de ter muitos espaços e muitas temporalidades que convivem simultaneamente. Para 0 autor, esses espaços constituem esferas de significação social - casa, rua e outro mundo -, que fazem mais do que separar contextos e configurar atitudes, pois contêm visões de mundo ou éticas específicas:

Qualquer evento pode ser sempre "lido" (ou interpretado) por meio do código da casa e da família (que é avesso à mudança e à história, à economia, ao individualismo e ao progresso), pelo código da rua (que está aberto ao legalismo jurídico, ao mercado, à história linear e ao progresso individualista) e por um código do outro mundo (que focaliza a idéia de renúncia do mundo com suas dores e ilusões e, assim fazendo, tenta sintetizar os outros dois). Os três códigos são diferenciados, mas nenhum deles é exclusivo ou hegemônico, em teoria. (DaM atta, 1987, p. 52)

Nesse sentido, o normal, 0 esperado e 0 legitimado é que casa, rua e outro mundo demarquem fortemente mudanças de atitudes, gestos, roupas, assuntos e papéis sociais para todos os membros de nossa sociedade. Desse modo, o comportamento do indivíduo diferenciase de acordo com o ponto de vista de cada uma dessas esferas de significação. 0 que pude observar entre as profissionais do sexo é que as representações que elas fazem da casa e da rua é o que determina suas atitudes, gestos, vestimenta e papéis sociais. Nos depoimentos dessas mulheres, há sempre uma intenção de demarcar uma fronteira simbólica entre esses dois espaços. Em relação aos gestos e atitudes, elas afirmam que o comportamento que elas têm no "ambiente de trabal ho" é muito diferente do que têm em casa. Quando estão no trabalho, seu comportamento visa à interação com os atores presentes no ambiente, seus pares sociais, as profissionais do sexo e, principalmente, 0 cliente, sendo que a interação com esse último dá-se através de um jogo de sedução que implica uma performance composta de gestos, falas e atitudes para atraí-lo. A o se reportarem às atitudes que têm em suas casas ou no ambiente familiar, elas enfatizam o decoro e o recato, utilizando um discurso embasado na conduta moral convencional:

Eu nunca levei um homem pra dormir na minha casa, eu acho supererrado. A minha menina tem dezoito anos, às vezes vai pra festa com o namorado dela e umas duas vezes el e dormiu lá em casa, eu falei pra ela - Não! Você já viu eu trazer um homem pra dormir aqui? Ela falou: Não. Isso é pra você também não trazer. Então não vamos misturar as coisas! Cada coisa no seu lugar! É ou não é? E assim eu vou levando a vida. (Dados de entrevista)

0 que se observa é que as mulheres criam uma barreira simbólica entre o comportamento que têm na rua e aquele assumido no ambiente familiar, onde se pautam por valores morais tradicionais da nossa sociedade. Outra questão que perpassa a visão dessas mulheres em relação a esses dois espaços simbólicos - casa e rua - está associada a símbolos de estigma, como a forma de se vestirem ou até mesmo a maquiagem, o que remete, mais uma vez, à representação do corpo. $\mathrm{Na}$ avaliação das entrevistadas, há diferenças na forma como se vestem quando estão se prostituindo e quando estão em outros ambientes. Elas preocupam-se também em não manter, até mesmo no trabalho, uma aparência muito extravagante:

$\mathrm{Na}$ maquiagem, eu acho que eu não preciso ficar com o rosto fantasiado pra me mostrar, pra me aparecer. Eu acho que se você colocar uma pintura muito exagerada, você fica muito vulgar, muito cheguei! M uito escrito na sua cara, eu sou uma puta! Já nas roupas, eu uso umas roupas mais assim quando estou trabaIhando. ${ }^{2}$ Porque eu acho assim, vamos supor, com essa blusa aqui, até que não é muito

2. No momento da entrevista ela estava vestida com uma blusa bem curta que ressaltava os seios e uma minissaia também bastante curta. 
escandal osa pra entrar em qual quer lugar e sair. M as com essa saia, se eu tiver que sair pra outro lugar eu coloco uma blusa mais discreta. Q uando eu vou sair eu coloco uma blusa e um batom e só, assim eu posso entrar e sair de qualquer lugar, entendeu? A gora se você tá com uma roupa muito vulgar, com uma maquiagem muito vulgar, todo mundo te repara, todo mundo te olha, todo mundo comenta. Então eu acredito assim, a pessoa na simplicidade ela entra em qualquer lugar. (D ados de entrevista)

Para entender outras dimensões identitárias dessas mulheres, é preciso compreender o que el as fazem quando não estão se prostituindo, ou seja, descobrir como é sua vida cotidiana fora do local de trabalho. 0 que se percebe é que a maioria dos trabal hos sobre a prostituição estão voltados quase sempre para o entendimento das dinâmicas, das relações e das representações presentes nesse universo, deixando de ressal tar que a mulher profissional do sexo tem uma vida que não se resume apenas à prostituição, pois negocia constantemente com outras esferas e papéis que não se restringem ao ambiente da prostituição e ao ofício de prostituir-se.

Há uma idéia generalizada de que as mulheres que se prostituem levam uma vida desregrada, promíscua, sem responsabilidades e sem vínculos familiares e afetivos. No entanto, ao focalizar a rotina de suas vidas, pude perceber que, quando não estão trabal hando, suas atenções voltam-se para a casa e os filhos. A o serem questionadas em entrevistas sobre o que fazem quando não estão no trabalho, todas as entrevistadas me disseram que ficam em casa cuidando dos filhos e envolvidas com os afazeres domésticos. Como pode ser observado na afirmação de uma entrevistada: "Quando não estou aqui eu fico em casa, ajudo menino a fazer tarefa, quando eu não venho pra cá eu levo as minhas meninas no colégio, eu pego elas, ensino elas a fazer tarefa, faço almoço, faço janta, aquela rotina". De depoimentos como este, inferimos quea rotina de uma mulher profissional do sexo não difere da rotina diária de qualquer dona de casa que trabalhe fora, o que parece desmistificar a idéia de que a mulher que se prostitui leva uma vida desregrada e sem compromissos.
Outra atividade de lazer bastante recorrente entre as mulheres pesquisadas é freqüentar clubes em companhia dos filhos. Em nenhuma das entrevistas, foram mencionadas, como forma de lazer, atividades como ir a bares ou a boates. Eventualmente, elas vão a festas nas casas de familiares ou amigos. Um dado que me chamou atenção nos depoimentos foi 0 de que é bastante comum entre elas freqüentar al guma igreja pelo menos uma vez por semana, sendo as igrejas evangélicas as mais procuradas. A representação que elas fazem do ato de freqüentar uma igreja está embasada na justificativa nos poderes divinos e sagrados:

Tem mais ou menos uns seis meses que eu freqüento uma igreja. Porque eu acho assim, já tá difícil a gente aqui nesta rua, ainda mais sem uma religião, aí não tem como. Você sabe o que é isso aqui? I sso aqui é um encosto e você tem que lutar! Você tem que lutar! Pra D eus te tirar desse encosto e você se livrar dessa prostituição! Você tem que buscar a Deus pra você se libertar disso aqui. É o que eu mais quero! É o que eu mais peço! Eu chego na igreja e eu oro! Eu peço! Eu peço pra me tirar daquele lugar! M e tira daquele lugar! E eu sei que tá perto deu sair disso aqui! (D ados de entrevista)

Para o entendimento do que representa para essas mulheres o espaço da igreja, reportome a DaM atta (1987), que entende a casa, a rua e 0 outro mundo como esferas de significação social. Dentro dessa perspectiva, faço uma anal ogia entre a igreja e a chamada esfera do outro mundo, pois, na concepção do autor, caso pudesse existir uma zona neutra entre a casa e a rua, ela seria proporcionada por essa última, que, na sua concepção, simplesmente abre as portas para a renúncia ritual izada deste mundo com suas contradições, dores e ilusões. 0 que pude observar é que, entre as mulheres entrevistadas, o espaço da igreja representaria essa zona neutra, pois estaria entre o mundo da casa e o mundo da rua, sendo buscado como um refúgio momentâneo para angústias diárias.

Outra questão abordada na pesquisa com essas mulheres está relacionada às suas expectativas ou planos para o futuro. A o serem questionadas sobre isso, as entrevistadas afirmam a vontade de sair da prostitui ção, sendo recorrente 
entre elas a fixação de uma data precisa para deixarem de se prostituir. Na maioria dos casos, são datas muito próximas, tendo como limite apenas o prazo de alguns meses. Embora no grupo pesquisado a prostituição seja encarada como uma atividade provisória ou momentânea, o tempo de prostituição das mul heres com quem pude conversar ou entrevistar é entre quatro e vinte anos. 0 que se pode constatar é que, mesmo tendo plena consciência de que o desejo de saírem da prostituição raramente se concretiza, a fixação utópica de um prazo torna suportável para elas o desempenho cotidiano de um ofício estigmatizado.

A bstract: The present article is part of a research accomplished a group of women that they prostitute in the city of Goiânia, Goiás, that resulted in my master's degree dissertation. Starting from data dotained through empiric research, that study discusses aspects related to the construction of the professional' $s$ of the sex identity, as the representations of the booly and the stigmatization process. From the theoretical point of view, my reflexion seeks to contribute to remove the essence and the naturalization of the concept of the identity in a perspective that understands it as procedural, dynamical and relational.

K ey words: identity; book; prostitution.

\section{Referências}

A LVES, Paulo César; M INAY O, M aria Cecília deS. (Org.). Saúde e doença: um ol har antropológico. Rio de Janeiro: Fiocruz, 1994.

BRA SIL. M inistério da Saúde. Profissionais do sexo: documento referencial para ações de prevenção das DST e da A ids / Secretaria de Políticas de Saúde, Coordenação Nacional de DST e Aids. Brasília: M inistério da Saúde, 2002.

B OLTANSK I, Luc. As classes sociais e o corpo. Rio deJ aneiro: Graal, 1989.

CARDOSO DE OLIVEIRA, Roberto. 0 trabalho antropológico: ol har, ouvir e escrever. Revista de Antropologia. São Paulo, v. 39, n. 1, p. 13-37, 1996.

Os (des)caminhos da identidade. Revista Brasileira de Ciências Sociais. São Paulo, v. 15, n. 42,2000.

CA RVA LH O, J anaína de Cássia. Corpo feminino e mutilação: um estudo antropológico. Goiânia: Ed. daUFG, 2002.
DA M ATTA, Roberto. A casa \& a rua. Rio de J aneiro: Guanabara, 1987.

ESPIN HEIRA, G ey. D ivergência e prostituição: uma análise sociológica da comunidade prostitucional do M aciel. Salvador: Fundação Cultural do Estado da B ahia, 1984.

FABREGAS-M ARTÍNEZ,A nalsabel; BENEDETTI, $\mathrm{M}$ arcos Renato $(\mathrm{Org}$.). Na batalha: sexualidade, identidade e poder no universo da prostituição. Porto A legre: Dacasa Pal maria, 2000.

FERREIRA, Jakeline. 0 corpo signo. In: ALVES, Paulo César; M INAY O, M aria Cecília de S. (Org). Saúde e doença: um olhar antropológico. Rio de Janeiro: Ed. Fiocruz, 1994.

FREITAS, Renan Springer de. Bordel, bordéis: negociando identidades. Petrópolis: Vozes, 1985.

GA SPA R, M aria Dulce. Garotas de programa. Rio deJaneiro: Zahar, 1985.

GIDDENS, A nthony. A transformação da intimidade: sexual idade, amor e erotismo nas sociedades modernas. São Paulo: Unesp, 1993.

GOFFMAN, Erving. Estigma: notas sobre a manipulação da identidade deteriorada. Rio de J aneiro: LTC S.A ., 1988.

$H A L L$, Stuart. A identidade cultural na pósmodernidade. Rio de Janeiro: DP\&A, 2002.

LEA L, Ondina Fachel. (Org.). Corpo e significado: ensaios de antropologia social. Porto A legre: UFRGS, 2001

M A USS, M arcel. A s técnicas corporais. In: Sociologia e antropologia. São Paulo: EPU, 1974, v. 2.

RIOS, Roger Raupp. Prostitutas, michês e travestis: uma análise crítica do discurso jurídico sobre prostituição e suas conseqüências práticas. In: FÁBREGA S M A RTINEZ, A nal sabel; B ENEDETTI, $M$ arcos Renato. (Orgs.). Na batalha: sexualidade, identidade e poder no universo da prostituição. Porto A legre, RS: Dacasa Palmaria, 2000.

RODRIGUES, José Carlos. Tabu do corpo. Rio de J aneiro: A chiamé, 1979.

SANT'AN NA, Denise Bernuzzi. Cuidados de si e embelezamento: fragmentos para uma história do corpo no Brasil. In: (Org.). Políticas do corpo. São Paulo: Estaçã̃o Lỉiberdade, 1995.

SILVA, Tomaz Tadeu da (Org.). Identidade e diferença: a perspectiva dos estudos culturais. Petrópolis: Vozes, 2003.

WOODWA RD, K athryn. Identidade e diferença: uma introdução teórica e conceitual. In: SILVA, Tomaz Tadeu da. (O rg.). Identidade e diferença: a perspectiva dos estudos culturais. Petrópolis: Vozes, 2000. 